Prosiding Seminar Nasional Teknologi Informasi dan Kedirgantaraan : Transformasi Teknologi untuk Mendukung Ketahanan Nasional, Yogyakarta, 13 Desember 2018

SENATIK 2018, Vol. IV, ISBN 978-602-52742-0-6

DOI: http://dx.doi.org/10.28989/senatik.v4i0.253

\title{
INFLUENCE OF GMELINA WOOD ON MECHANICAL PROPERTIES AND MORPHOLOGY OF EPOXY COMPOSITES Agung Prakoso ${ }^{1)}$, Henny Pratiwi ${ }^{2)}$ \\ Program Studi Aeronautika \\ Sekolah Tinggi Teknologi Adisutjipto \\ Jl. Janti Blok R Lanud Adisutjipto Yogyakarta

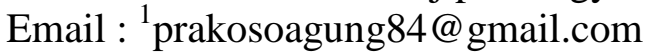

\begin{abstract}
Lignocellulosic filler such as gmelina wood flour is an alternative of synthetic reinforcements which is ecofriendly, abundant in nature and inexpensive. This research aims to investigate the effects of gmelina wood filler addition on tensile properties, impact strength and morphology of epoxy composites. Filler volume fractions evaluated were 10, 20, 30 and 40 percent with 30 mesh filler size. Hand lay-up method was used to manufacture the composites. Tensile strength, tensile modulus, elongation and impact strength were determined based on ASTM standard. Results show that filler addition up to some extents improves the mechanical properties of materials. The optimum tensile properties and impact strength are achieved when 10 percent filler is added into epoxy matrix. Further addition of filler degrades the tensile and impact properties of composites. This phenomenon is due to the existence of weak interfacial interaction between the gmelina wood filler and epoxy matrix for higher filler volume concentration beyond 10 vol. \%. The scanning electron micrograph of tensile fracture surface reveals that there are voids, agglomeration and pullout mechanism which are the cause of the composites failure.
\end{abstract}

Keyword: gmelina wood, composite, tensile, impact, filler

\section{Pendahuluan}

Dewasa ini, penggunaan material komposit yang terbuat dari plastik diperkuat serat atau serbuk berbahan alam mengalami peningkatan dikarenakan memiliki beberapa kelebihan seperti ketersediaan melimpah di alam, strength to weight ratio tinggi, dan kekuatan mekanik yang bisa di rekayasa sesuai dengan aplikasi jika dibandingkan dengan material logam. Kelebihan ini menyebabkan komposit diaplikasikan pada beberapa komponen penting di industri otomotif, kelautan dan bahkan industri pesawat udara. Delaminasi, yang merupakan perambatan retak pada komposit, telah menjadi tantangan tersendiri dalam manufaktur komposit. Terdapat beberapa penelitian yang membahas teknik pencegahan atau penundaan terjadinya delaminasi, diantaranya menggunakan beberapa variasi bahan penguat baik berupa serat maupun serbuk [1], persentase [2,3], perlakuan kimia [4] dan optimisasi proses manufaktur [5-6]. Penelitian mengenai optimisasi persentase filler mengungkap bahwa sifat mekanik komposit dan hubungan antarmuka matriks dan filler mengalami peningkatan disebabkan persentase penguat optimal. Bagaimanapun, konsentrasi filler yang cukup tinggi dapat menyebabkan aglomerasi dan sulitnya filler untuk dispersi ke dalam matriks [7-8].

Filler yang terbuat dari alam (bio-filler) merupakan bahan pengganti alternatif filler maupun serat sintetik memiliki sifat ramah lingkungan dan bahkan terdapat bio-filler yang merupakan limbah atau sisa produksi, seperti pada kasus ini. Filler ini digunakan untuk meningkatkan sifat komposit termasuk sifat mekanik dan morfologinya. Beberapa peneliti telah mengamati efek penambahan bio-filler terhadap sifat material. Bharathkumar dkk. [9] 
menguji pengaruh penambahan alga pada komposit vinylester terhadap kekuatan tarik, bending dan impak. Penelitian menunjukkan bahwa penambahan filler sampai batas tertentu dapat meningkatkan kekuatan tarik, bending dan impak komposit. Huang dkk. [10] mengamati efek penambahan ampas tebu pada komposit poly(vinyl chloride) dan menyimpulkan bahwa inklusi bio-filler meningkatkan kekuatan tarik, modulus tarik, energi impak, kekerasan dan sifat termalnya. Penambahan bio-filler seperti fly ash dan serbuk kulit padi juga mampu memperbaiki sifat mekanik komposit hibrid serat rami/epoksi, serat rami/polyester [11], dan serat gelas/epoksi [12]. Kajian saat ini membahas kandungan filler optimum terhadap sifat mekanik dan morfologi komposit kayu gmelina-epoksi.

\section{Metodologi Penelitian}

Kayu gmelina dalam bentuk serbuk diayak menggunakan saringan 30 mesh dengan variasi fraksi volume 10, 20, 30 dan 40\%. Serbuk kayu kemudian dicampur dengan resin epoksi (Bisphenol A- epichlorohydrin) Bakelite EPR 147 dan hardener versamid 140 selama 15 menit. Setelah bahan tercampur secara merata, campuran dituang ke dalam cetakan dan dikeringkan pada suhu 50 derajat Celcius selama 2 jam selanjutnya dibiarkan selama 15 hari pada suhu ruangan. Mesin uji tarik Torsee AMU-5-DE digunakan untuk mengevaluasi spesimen tarik berdasarkan standar ASTM D638-91. Pengujian impak Charpy (Hung Ta Instrument dengan massa pendulum $23.870 \mathrm{Kg}$ ) dilakukan untuk mengetahui ketahanan impak dan energi yang diserap komposit berdasarkan standar ASTM D790-02. Permukaan patahan spesimen tarik kemudian diteliti menggunakan scanning electron microscope (SEM) untuk mengamati efek filler terhadap interaksi antarmuka filler dan matriks.

\section{Hasil dan Pembahasan}

Deformasi diukur untuk semua spesimen tarik dimana diberikan gaya 2000 Newton. Deformasi untuk material ulet lebih besar jika dibandingkan dengan material getas atau kaku dimana besar beban yang diberikan sama untuk semua spesimen. Sifat elastis matriks, susunan filler dalam matriks, interaksi filler dan matriks dan kandungan volume filler dalam komposit merupakan beberapa faktor yang berkontribusi terhadap kekuatan material. Interaksi matriks/filler dipengaruhi oleh kemampuan filler untuk masuk atau menyusup ke dalam matriks, sifat alami permukaan filler dan aspek rasio filler.

Hasil pengujian tarik menunjukkan bahwa 10 persen fraksi volume filler dapat menyatu secara baik dengan matriks dan tidak membentuk gumpalan. Hal ini menyebabkan kekuatan tarik, modulus tarik dan elongasi bernilai optimum (Gambar 1). Komposit yang mengandung lebih dari 10 persen filler memiliki viskositas lebih tinggi sehingga terdapat banyak partikel yang bergumpal dalam matriks. Hasil pengujian juga menunjukkan bahwa nilai elastisitas komposit bervariasi terhadap fraksi volume filler yang disebabkan penambahan filler mengubah sifat ulet matriks. Dalam kasus ini, semakin rendah fraksi volume filler, semakin tinggi keuletan nya karena fraksi volume rendah memiliki jarak antar partikel yang lebih besar sehingga rantai polimer bisa bergerak lebih luas. Kandungan filler yang tinggi menyebabkan pendeknya jarak antar partikel sehingga mobilitas polimer terbatas menyebabkan keuletan rendah dan kekakuan tinggi. Hal ini sama dengan hasil penelitian yang dilakukan oleh [1], [2] dan [13]. Mereka menyatakan bahwa fraksi volume filler yang tinggi menurunkan sifat mekanik komposit. 


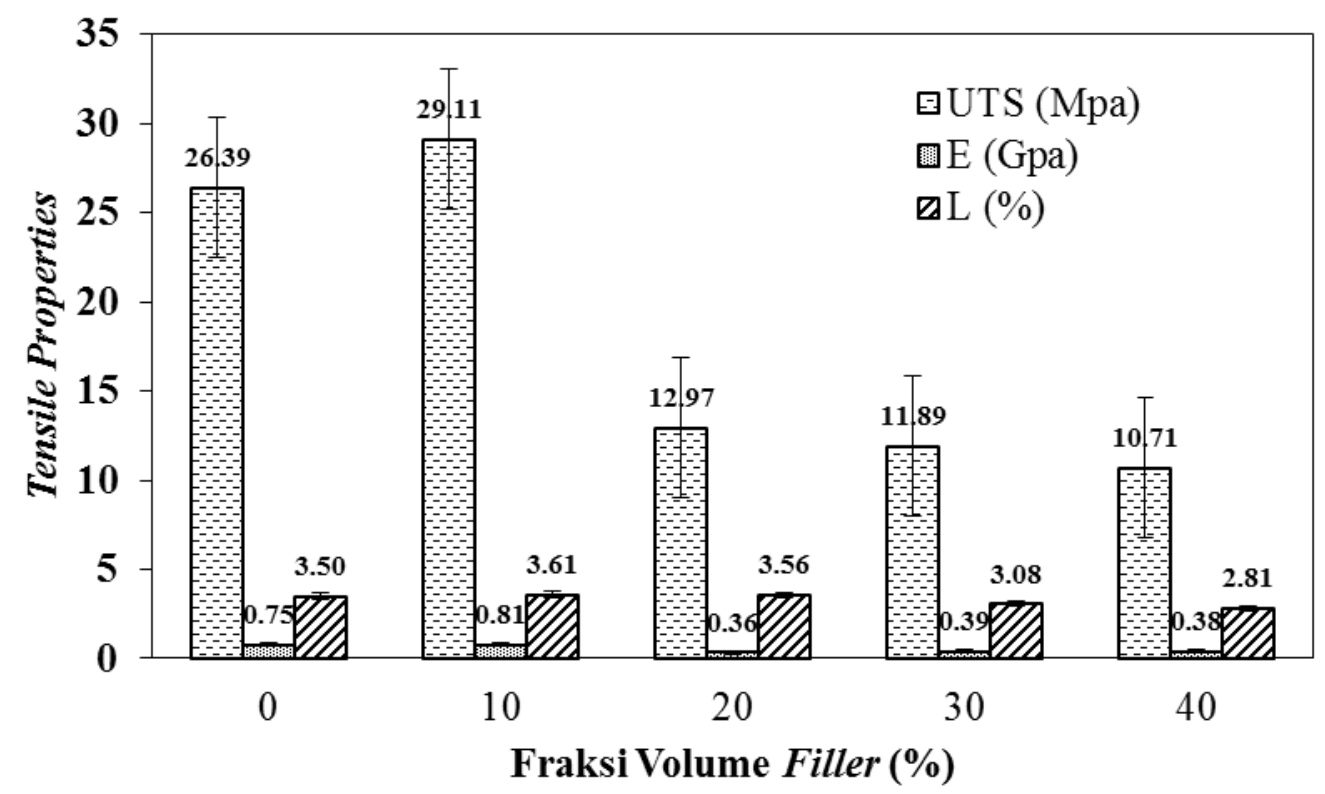

Gambar 1 Efek fraksi volume filler terhadap sifat tarik (tensile properties) komposit serbuk kayu gmelina dengan matriks epoksi

Kemampuan komposit untuk menahan retak di bawah pengaruh beban tiba-tiba dapat dikatakan sebagai kekuatan impak. Efek fraksi volume terhadap kekuatan impak komposit serbuk kayu gmelina dengan matriks epoksi dapat dilihat pada gambar 2. Berdasarkan hasil pengujian dapat disimpulkan bahwa semakin tinggi fraksi volume filler, semakin rendah kekuatan impak nya dimana kekuatan impak tertinggi diperoleh pada komposit dengan fraksi volume filler 10 persen. Bagaimanapun, penambahan filler lebih jauh dapat menurunkan kekuatan impak komposit. Hal ini mungkin disebabkan adanya interaksi yang kurang baik antar permukaan serbuk kayu gmelina dan matriks polimer untuk fraksi volume lebih besar dari 10 persen. Hal ini didukung oleh penelitian lain $[2,9,15]$ yang mengungkapkan bahwa penambahan filler sampai pada kadar tertentu menurunkan energi perambatan retak yang selanjutnya menurunkan kekuatan impak komposit.

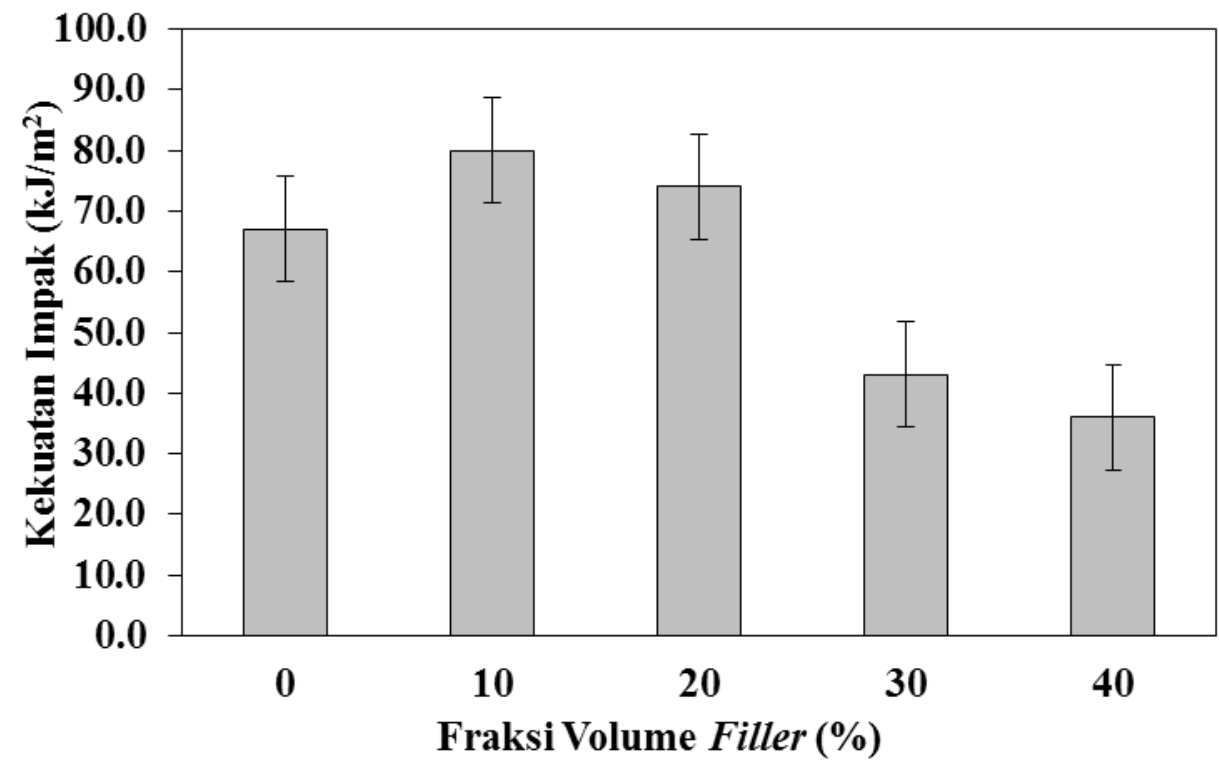

Gambar 2 Efek fraksi volume filler terhadap kekuatan impak komposit serbuk kayu gmelina dengan matriks epoksi 
Di sisi lain, kehadiran gelembung udara (void) dan pull-out berkontribusi besar terhadap fenomena kegagalan komposit (Gambar 3). Berdasarkan hasil scanning electron micrograph (SEM) pada permukaan patahan uji tarik, dapat dilihat bahwa terdapat void, aglomerasi, dan mekanisme pull-out. Void dan pullout ditunjukkan dengan tanda panah sedangkan aglomerasi (penggumpalan serbuk) ditunjuk dengan lingkaran putus-putus. Mekanisme pull-out ini disebabkan hubungan antar muka yang kurang baik antara filler yang terbuat dari alam (lignocellulosic) dan matriks polimer sementara void disebabkan adanya udara yang terperangkap dalam komposit selama proses manufaktur. Kedua faktor ini meyebabkan transfer beban antara filler dan matriks kurang efektif [15].

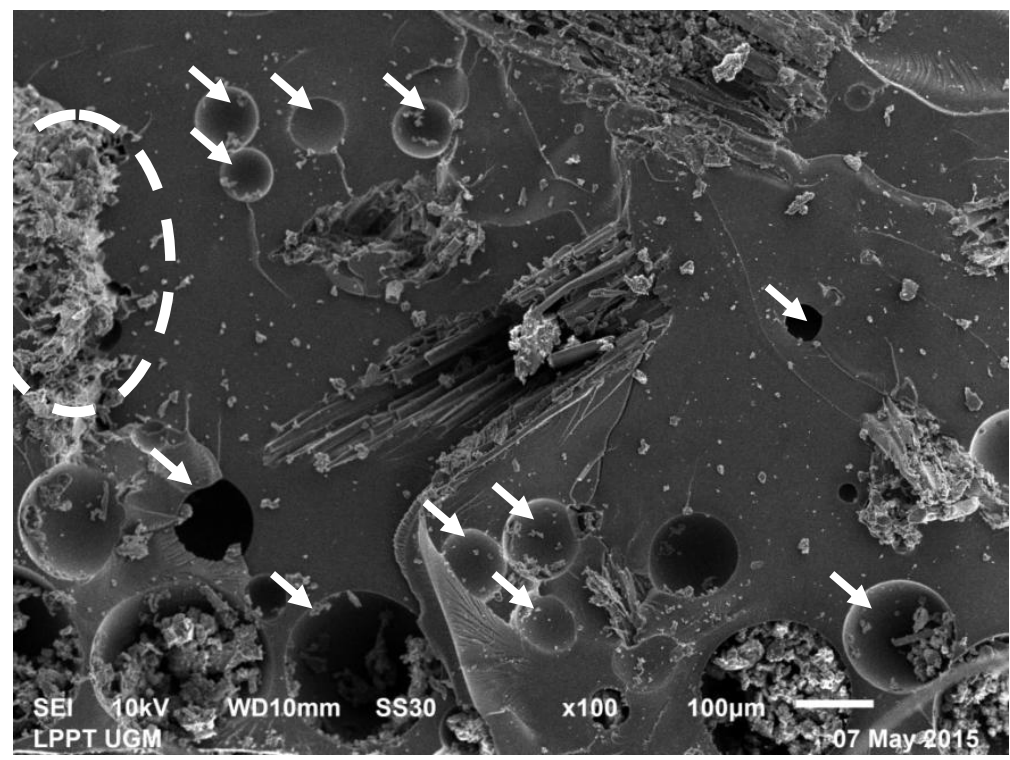

Gambar 3 Hasil pengujian SEM pada permukaan patahan uji tarik komposit serbuk kayu gmelina dengan matriks epoksi

\section{Kesimpulan}

Efek penambahan serbuk kayu gmelina terhadap sifat mekanik dan morfologi pada komposit bermatriks epoksi diamati pada penelitian ini. Hasil pengujian tarik dan impak menunjukkan bahwa 10 persen fraksi volume serbuk merupakan konsentrasi optimum filler yang terkandung dalam matriks epoksi. Fraksi volume serbuk lebih besar dari 10 persen dapat menurunkan sifat mekanik komposit disebabkan adanya partikel yang tidak tercampur merata dengan matriks. Pengamatan terhadap permukaan patahan spesimen uji tarik menunjukkan bahwa terdapat void, aglomerasi, dan fenomena pull-out yang merupakan penyebab utama kegagalan komposit.

\section{Ucapan Terimakasih}

Penulis mengucapkan terima kasih kepada Sekolah Tinggi Teknologi Adisutjipto yang telah memberikan dukungan dana pada penelitian ini.

\section{Daftar Pustaka}

[1] Sajith, S, Arumugam, V, Dhakal, HN (2017). Comparison on Mechanical Properties of Lignocellulosic Flour Epoxy Composites Prepared by Using Coconut Shell, Rice Husk and Teakwood as Fillers, Polymer Testing, Vol. 58, pp. 60 - 69.

[2] Pratiwi, H, (2018). Influence of Albasia Wood on Mechanical Properties and Morphology of Epoxy Composites, Jurnal Ilmiah Angkasa, Vol. 10, No. 2. 
[3] Safaee, S, Yasrebi, B, (2017). Effect of an Increase in Nano-Filler Content on the Mechanical Properties of High-Leucite Composite Resins Useable in Dentistry, Crescent Journal of Medical and Biological Sciences, Vol. 4, No. 3, pp. $144-149$.

[4] Sosiati, H, Supatmi, Wijayanti, DA, Widyorini, R, Soekrisno, 2014, Properties of the Treated Kenaf/Polypropylene (PP) Composites, Advanced Materials Research, Vol. 896 , pp. $566-569$.

[5] Nugroho, F. (2016), Studi Pengaruh Proses Manufaktur Komposit Bermatrik Epoksi Terhadap Kekuatan Tarik dan Impak pada Komposit Hybrid Berpenguat Serbuk Kayu Albasia dan Serat Gelas, Seminar Nasional SENATIK STT Adisutjipto Yogyakarta, Vol. 2, pp. $41-47$.

[6] Pratiwi, H. (2016). The Effects of Mixing and Curing on Morphological and Mechanical Properties of Epoxy-Albasia Composites, Conference SENATIK STT Adisutjipto Yogyakarta, Vol. 2, pp. 55 - 61.

[7] Alzarrug, FA, Dimitrijević, MM, Heinemann, RMJ, Radojević, V, Stojanović DB, Uskoković, PS, Aleksić, R. (2015). The Use of Different Alumina Fillers for Improvement of the Mechanical Properties of Hybrid PMMA Composites, Materials and Design, Vol. 86, pp. $575-581$.

[8] Herrera-Ramírez, LC, Castell, P, Fernández-Blázquez, JP, Fernández, A, de Villoria, RG. (2015). How Do Graphite Nanoplates Affect the Fracture Toughness of Polypropylene Composites, Composite Science and Technology, Vol. 111, pp. 9 - 16.

[9] Bharathkumar, B, Sasikumar, K, Bharathiraja G, Jayakumar, V, 2018, Study of Mechanical Properties of Algae Filler Vinylester Composite, International Journal of Pure and Applied Mathematics, Vol. 119, No. 12, pp. 15667 - 15676.

[10] Huang, Z, Wang, N, Zhang, Y, Hu, H, Luo, Y.(2012). Effect of Mechanical Activation Pretreatment on the Properties of Sugarcane Bagasse/Poly(Vinyl Chloride) Composites, Composites: Part A, Vol. 43, pp. $114-120$.

[11] Pratiwi, H (2018). The Effects of Mt. Kelud Volcanic Ash on Morphological and Mechanical Properties of Hemp Fabric Reinforced Polyester and Epoxy Composites, AIP Conference Proceedings, Vol. 2014, Issue 1, pp. 020094

[12] Rout, AK, Satapathy, A.( 2012). Study on mechanical and tribo-performance of ricehusk filled glass-epoxy hybrid composites, Materials and Design, Vol. 41, pp. 131 141.

[13] Manikandan, V, Richard, S, Thanu, MC, Rajadurai, JS. (2015). Effect of Fly Ash as Filler on Mechanical \& Frictional Properties of Jute Fiber Reinforced Composite, International Research Journal of Engineering and Technology, Vol. 02, Issue 07, pp. $154-158$.

[14] Bengtsson, M, Baillif, L, Oksman, K (2007). Extrusion and Mechanical Properties of Highly Filled Cellulose Fibre-Polypropylene Composites, Composites Part A, Vol. 38, Issue 8, pp. 1922 - 1931.

[15] Obasi, HC, Iheaturu, NC, Onuoha, FN, Chike-Onyegbula, CO, Akanbi, MN, Ezeh, VO, (2014). Influence of Alkali Treatment and Fibre Content on the Properties of Oil Palm Press Fibre Reinforced Epoxy Biocomposites, American Journal of Engineering Research, Vol. 3, Issue 2, pp. 117 - 123. 